\title{
90 Neonatal diseases II
}

\author{
Brian P. Hackett, Jeffrey Dawson, Akshaya Vachharajani, Barbara Warner, \\ and F. Sessions Cole
}

\section{RESPIRATORY PROBLEMS IN TERM INFANTS}

Unlike the typical respiratory problems of prematurely delivered newborns that result from inadequate surfactant production, the mechanisms of respiratory problems in term infants ( $\geq 37$ weeks of gestation) are associated with inadequate pulmonary perfusion (e.g., persistent pulmonary hypertension of the newborn) as well as surfactant deficiency due to both inadequate production (e.g., in the late preterm infant) and inactivation [e.g., meconium aspiration syndrome (MAS), congenital pneumonia]. Finally, both spontaneous airleaks and congenital abnormalities of airway, pulmonary parenchyma, or pulmonary vascular development (e.g., congenital diaphragmatic hernia, alveolar-capillary dysplasia) present as respiratory distress in the term newborn. Although term infants are less likely to suffer from respiratory problems than preterm infants, their risk for respiratory distress has been estimated at $0.6 \%$ in one large prospective study (1) and their risk for severe respiratory distress that requires mechanical ventilation at $\sim 0.2 \%$ (2).

\section{MAS}

Although most infants delivered after exposure to meconiumstained amniotic fluid will exhibit no symptoms, a subgroup may develop severe respiratory failure. Understanding the pathophysiology of this subgroup has been enhanced by understanding fetal lung physiology. Net fluid flow in the fetal lung results from an egress of fluid from pulmonary epithelial cells into future airspaces and airways. The flow of fetal lung fluid across the glottis into the amniotic cavity keeps contaminants in the amniotic fluid (e.g., meconium, squamous cells, and blood) downstream from pulmonary epithelial cells in utero. Aspiration of these agents may occur if the fetus is "gasping," a fetal behavior associated with severe hypoxia or ischemia. Exposure of the pulmonary epithelium to meconium leads to evidence of significant injury with elaboration of cytokines associated with inflammation, altered surfactant metabolism, and histologic evidence of airspace overdistention. These pathophysiologic mechanisms help explain the ventilatory problems associated with MAS and increased risk of airleaks (3). The associated hypoxia and acidosis, particularly if preceded by prolonged intrauterine distress with increase in the thickness of the muscularis layer in the smaller pulmonary branch vessels (4), contribute to failure to achieve normal pulmonary vasorelaxation and to worsening hypoxia and hypercarbia in a cyclic fashion. Thus, both severe pulmonary parenchymal injury and pulmonary hypertension contribute to the presentation and must be treated.

MAS occurs in $0.6 \%$ to $0.7 \%$ of all newborn infants with any respiratory symptoms and in $0.04 \%$ of newborn infants who require mechanical ventilation $(2,5,6)$. Although risk for other common respiratory problems [e.g., transient tachypnea of the newborn (TTN) or respiratory distress syndrome (RDS)] decreases with advancing gestational age, risk for MAS increases with advancing gestational age. Approximately onethird of symptomatic infants will require mechanical ventilation, and despite surfactant replacement and availability of high-frequency oscillatory ventilation (HFOV) and nitric oxide (NO) treatment, mortality is reported in $2.5 \%$ of infants who require ventilatory support (down from 12\% before widespread adoption of HFOV and NO).

Over the last decade, approaches to intrapartum and immediate postpartum prevention of MAS have moved away from attempts to evacuate the upper airway of meconium by obstetricians at delivery of the head and by pediatricians after the delivery is complete. These interventions were found to be helpful in small historical control studies in the 1970s. However, larger randomized controlled trials reported in the 1990s failed to demonstrate any improvement in outcomes and raised concerns about associated iatrogenic injury to the upper airway in some infants. The official 2005 recommendation of the American Heart Association and the American Academy of Pediatrics makes clear that in the setting of infants born with thick meconium staining, the priority is to reserve intubation only for the infants who are most depressed at birth and not routinely to aspirate the mouth and nose (7). Similarly, although initial randomized studies of amnioinfusions for meconium-stained amniotic fluid found a beneficial effect on neonatal respiratory outcomes without increased maternal morbidity, a large multicenter randomized study (8) reported no routine benefit from amnioinfusion. The American College of Obstetrics and Gynecology revised its practice guideline to indicate that although amnioinfusion remains an appropriate intervention for treatment of fetal distress (with or without meconium-stained amniotic fluid) evaluated by heart rate monitoring, it is not effective for reduction of risk of MAS $(9,10)$.

\section{TTN}

First described by Mary Ellen Avery in 1966 (11), this selflimited (hours to a few days) condition is characterized by presentation within the first few hours of life with tachypnea, a radiographic picture of increased perihilar pulmonary vascular markings, fluid in the pulmonary lobar fissure, and increased lung volumes. Both the severity and duration of symptoms vary but are generally less intense than those seen in respiratory disorders like MAS or congenital pneumonia. As noted earlier, net fetal lung liquid production leads to egress of fluid into the amniotic cavity. Just prior to birth, this 
chloride-rich fluid production by the lung epithelium switches to fluid resorption driven by amiloride-sensitive sodium channels. The reversal of chloride and water transport leads to a decrease in total lung water before delivery. This process is dependent on long-term, developmentally regulated changes in the expression of sodium channels and their adrenoceptor sensitivity, more acute changes in ambient catecholamine levels associated with labor and delivery, and transition to the relatively oxygen-rich postnatal environment (12). Failure of this process of adaptation to the extrauterine environment in the absence of infection, surfactant deficiency or inactivation, or relevant birth defects is believed to cause the symptom complex known as TTN.

In keeping with this proposed mechanism, the risk factors associated with higher risk of TTN are those that interfere with normal adaptation from placenta-dependent gas exchange in utero to lung-dependent gas exchange in the extrauterine environment. Shorter gestation may lead to lower levels of expression of critical components of the sodium channel assembly, its catecholamine regulators, and surfactant (the risk of developing TTN increases with decreasing gestational age). Additionally, absent or shortened labor (e.g., in the settings of elective cesarean section without labor or of rapid second phase of labor) provides less time for alveolar fluid resorption and is associated with the development of TTN. Finally, disease risk may be increased by genetic factors, for example, polymorphisms in $B$ adrenoceptor gene (13). Recent studies have reinforced the association of TTN with both earlier gestational age and cesarean delivery mode (14-16).

\section{RESPIRATORY DISTRESS IN PRETERM INFANTS}

Despite advances in the care of infants born prematurely, prematurity (delivery at $<37$ weeks of gestation) remains one of the leading causes of neonatal death (17). The incidence of RDS, a major complication of prematurity, is directly related to lower gestational age at birth. The incidence of RDS in infants born at 25 weeks of gestation approaches $100 \%$. At 27 weeks of gestation, the incidence decreases to approximately $85 \%$, at 30 weeks of gestation to $55 \%$, at 32 weeks of gestation to $30 \%$, and by 35 weeks of gestation to $10 \%$ (18). In addition to prematurity, other factors that predispose to RDS include male gender, European ancestry, maternal diabetes, perinatal hypoxemia, hypothermia, multifetal pregnancy, and caesarean delivery (19). An increase in the rate of preterm deliveries over the last several years, attributable primarily to infants delivered between 34 and 37 weeks of gestation (late preterm infants) (See section below entitled "Late Preterm Neonates."), has contributed significantly to the burden of newborn respiratory distress (20).

In 1959, Mary Ellen Avery and Jere Mead described the relationship between preterm birth, lung surface tension, and RDS (21). Since that time, understanding the biology of pulmonary surfactant and its role in preterm respiratory distress has been one of the triumphs of newborn medicine. This understanding has led to the use of exogenous surfactant replacement as a primary treatment for preterm RDS. Available surfactant preparations include bovine- or porcinederived products and synthetic surfactant preparations that are administered to preterm infants via endotracheal tube. Multiple studies have demonstrated the efficacy of exogenous surfactant in reducing newborn mortality and airleaks, especially when given as multiple doses early after birth in a prophylactic, as opposed to rescue, manner $(22,23)$. Although a consistent reduction in the development of chronic lung disease (bronchopulmonary dysplasia) in preterm infants treated with surfactant has not been demonstrated, there is evidence that the severity of chronic lung disease has decreased in the era of surfactant therapy (24). Combined management strategies, for example, surfactant treatment and early extubation to continuous positive airway pressure (CPAP), show promise in decreasing not only the severity but the incidence of chronic lung disease in preterm infants with RDS as well $(25,26)$.

In the late 1960s, Graham Liggins made the seminal observation that lambs exposed in utero to corticosteroids and delivered prematurely had less respiratory distress, more mature appearing lungs, and decreased mortality (27). By 1972, the first human trial demonstrating the efficacy of antenatal corticosteroids in reducing RDS in preterm human infants had been completed (28). Since the 1970s, multiple clinical trials have demonstrated the effectiveness of antenatal glucocorticoid treatment of women in preterm labor in reducing the incidence and severity of RDS (29). Although significant concern has been raised regarding the association of postnatal steroid treatment of preterm infants with poorer neurodevelopmental outcomes, there has been no consistent evidence that administration of antenatal corticosteroids results in neurodevelopmental delay $(30,31)$.

The identification of genetic mutations that result in lethal respiratory failure in newborn infants has led to the discovery of genetic polymorphisms associated with an increased risk of respiratory distress in the premature newborn (32). Polymorphisms associated with an increased risk of RDS in preterm infants have been identified in the surfactant protein$A$, surfactant protein- $B$, surfactant protein- $C$, and the ATPbinding cassette transporter A3 (ABCA3) genes (33-35). Additionally, polymorphisms associated with preterm RDS have also been identified in genes not directly related to surfactant synthesis and secretion including mannose-binding lectin, interleukin-10, and the G protein-coupled receptor for asthma susceptibility (36-38). Elucidating the interactions between and among genetic variants, environment, and developmental factors may lead to novel management strategies in preterm infants with RDS.

\section{LATE PRETERM NEONATES}

\section{Terminology and Epidemiology}

An expert panel convened by the National Institute of Child Health and Human Development in July, 2005, recommended that infants born between 34 0/7 weeks (day 239) and 36 $6 / 7$ weeks (day 259) of gestation be referred to as late preterm $(39,40)$. Late preterm infants account for 360,000 of more than 4 million births in the United States (40). Davidoff and Dias et al. found that two-thirds of the last decade's increase in the rate of all preterm births was associated with an increase in the rate of late preterm births. Also noteworthy was that $74.1 \%$ of all singleton preterm births in 2002 occurred at 34, 35, and 36 weeks of gestation (41). Late preterm births also accounted for $61 \%$ of preterm multiple births (41). Since late preterm infants constitute such a large proportion of preterm infants, 
Table 1 Neonatal Infections by Timing of Onset

$\begin{array}{lccc}\text { Onset } & \text { Transmission } & \text { Risk Factors } & \text { Predominant Organisms } \\ \begin{array}{l}\text { Early } \\ \text { Birth to 2-7 days }\end{array} & \text { Vertical } & \text { Maternal colonization/infection } & \text { Group B Streptococcus } \\ & & \text { Prolonged premature rupture } & \text { Escherichia coli } \\ \text { Late } & \text { Prematurity } & \text { Coagulase-negative } \\ >2-7 \text { days } & \text { Verizontal } & \text { Invasive hardware/procedures } & \text { staphylococci } \\ \text { to } 1 \text { month } & \text { common } & \text { (vascular catheters, } & \text { Staphylococcus aureus } \\ & & \text { endotracheal tubes, surgery) } & \text { Escherichia coli } \\ & & \text { Environmental contact } & \text { Pseudomonas species } \\ & & \text { Prematurity } & \text { Candida }\end{array}$

even a modest increase in their birth rate can have a significant impact on infant outcomes and health-care costs. Maternal and fetal indications commonly associated with late preterm delivery include pre-eclampsia, multiple gestation, and abnormal presentations (42). A portion of late preterm delivery may be preventable, especially those births that result from "maternal preference" $(43,44)$.

\section{Morbidity}

Although historically called "near term," multiple morbidities associated with delivery between 34 and 37 weeks of gestation including respiratory distress, temperature instability, hypoglycemia, hyperbilirubinemia, apnea, seizures, and feeding problems, as well as higher rates of rehospitalization suggest that infants at these gestational ages are not prepared for successful fetal-neonatal transition $(39,45)$. For example, temperature instability, hypoglycemia, and jaundice were observed more frequently in late preterm infants $(10 \%$, $15.6 \%$, and $54.5 \%$, respectively) than term babies $(0 \%, 5.3 \%$, and $37.9 \%$, respectively) (45). Similarly, poor feeding was observed more frequently in late preterm than term infants $(77.8 \%$ vs. $45.3 \%)$. Apnea and bradycardia are seen in late preterm infants (45) with prevalence rates as high as 10\% (46). Late preterm infants are more likely to be evaluated with a complete blood count and blood culture and treated with antibiotics for 48 hours or 7 days compared with term babies (45) due to the difficulty of excluding sepsis as an underlying cause for multiple transitional symptoms including respiratory distress, hypothermia, and poor feeding. Delay in discharge among late preterm infants is more common as a result of these problems, with poor feeding as the most common reason for the delay (45). Respiratory complications are also prevalent among late preterm infants. The most common respiratory diagnoses among late preterm infants whorequire assisted ventilation include RDS, MAS, and pneumonia/sepsis (20). When compared with infants born at 37 to 42 weeks of gestation, the frequency of RDS is greater in late preterm infants ( $62 \%$ vs. $43 \%$ ), while the frequency of MAS is less (1.3\% vs. $9.7 \%)$ (20). Earlier studies also demonstrate increased need for mechanical ventilation as gestational age decreases among late preterm infants (1). Need for extracorporeal membrane oxygenator (ECMO) therapy for respiratory failure among late preterm infants has also been increasing (47). Among 15,590 infants in the Extracorporeal Life Support Organization National Registry treated with ECMO between 1989 and 2006, 2258 (14.5\%) were late preterm infants (47).

Death is more common in late preterm infants than term infants: risk of early neonatal death (birth to 28 days of age) is 5.2-fold greater, late neonatal death (28 days to 1 year of life) is 2.9-fold greater, and total infant mortality (all deaths from birth to 1 year of age) is 2.5 -fold greater $(39,48)$. Risk for increased morbidity also persists as evidenced by increased emergency department visits and rehospitalizations (49-51). Studies by Kinney et al. suggest that although the brain is more mature in late preterm than very preterm infants, it is still immature and can be disrupted or damaged by late preterm delivery (52). Substantial brain growth occurs between 34 and 41 weeks of gestation in utero: brain size increases by $33 \%$ in the final 6 to 8 weeks of gestation accompanied by a fivefold increase in brain volume. Late preterm infants can also develop periventricular leukomalacia, a white matter injury marker for subsequent cerebral palsy. The exact prevalence of brain pathology is unknown as systematic brain imaging is not currently recommended at this gestational age (52). Longer term follow-up studies suggest that late preterm infants are at increased risk for lower reading and math scores from kindergarten through elementary school and for participation in special educational programs (53).

\section{Conclusion}

Late preterm infants are at significantly greater risk for shortterm and long-term morbidity and mortality than was previously recognized.

\section{NEONATAL BACTERIAL SEPSIS}

Despite improvements in perinatal and newborn care, sepsis continues to be a leading cause of neonatal mortality, ranked sixth among causes of neonatal deaths in the United States (54). Neonatal sepsis refers to systemic infections that occur in infants $<1$ month of age. While infection with bacterial, viral, or fungal organisms may present identically in the newborn infant, this section will focus on bacterial infections. Among developed countries, the reported incidence of systemic bacterial infection ranges from 1 to 8 per 1000 live births $(55,56)$, with increasing incidence as birth weight decreases $(55,57)$. Neonatal sepsis is typically classified by timing of onset: early-onset sepsis (EOS) occurs from birth to a week of life, and late-onset sepsis (LOS) after the first week through the first month. The two categories differ not only by age of onset, but also by mode of transmission, risk factors, and causative organism (Table 1). For EOS, despite recent advances in preventing perinatal transmission with selective intrapartum chemoprophylaxis (see Chapter 74), group B Streptococcus (GBS) continues to be the most common causative organism. As the incidence of GBS has decreased, 
the contribution from Escherichia coli, particularly among the very low-birth weight population (VLBW, <1500 g), has increased. These two organisms account for $60 \%$ to $70 \%$ of all EOS $(55,58,59)$. Other less common pathogens include Enterococcus species, Streptococcus viridans, Staphylococcus aureus, a variety of gram-negative bacilli, and Listeria monocytogenes. For EOS in VLBW infants, the profile of organisms has recently changed. Gram-negative organisms are now the predominant causative organisms with ampicillinresistant E. coli accounting for approximately $40 \%$ of cases (60,61). Gram-positive organisms including GBS and coagulase-negative staphylococcus (CONS), account for another $45 \%$ of EOS cases among VLBW infants.

In LOS, gram-positive organisms predominate in all weight and gestational-age categories. For infants discharged from the hospital, the incidence of LOS caused by GBS has remained unchanged despite the use of intrapartum prophylaxis (62). In addition, LOS also occurs commonly in infants who require prolonged hospitalization in the neonatal intensive care unit (NICU). Gram-positive bacteria are the primary causative organisms with CONS accounting for approximately $40 \%$ of cases $(55,60)$. Other organisms include $S$. aureus with increasing frequency of methicillin resistance (MRSA), E. coli, and other gram negatives.

The clinical presentation of sepsis in the newborn is distinct from older children and adults. Signs and symptoms may often be subtle, nonspecific, and similar to a variety of neonatal illnesses. Common manifestations include temperature instability, tachypnea, lethargy, apnea, poor feeding, and abdominal distention $(63,64)$. Temperature instability is more commonly manifested as hypothermia, although temperatures above $37.8^{\circ} \mathrm{C}$ can be significant in a newborn infant when not associated with iatrogenic causes. The overlap of symptoms with respiratory, gastrointestinal, central nervous system, and metabolic disorders means that septicemia should be part of the differential diagnosis for infants with any of these findings.

The definitive diagnosis of sepsis is made by isolation of microorganisms from blood. Diagnosis by blood culture, however, is limited by test sensitivity, blood volume drawn, and can be contaminated by skin flora that may also be pathogenic in this population $(65,66)$. As a result, diagnosis and treatment are often based on a combination of clinical symptomatology and other diagnostic markers. Evaluating the white blood cell count and peripheral differential is an important first step in assessment but has variable sensitivity and poor specificity (67). Additional hematologic parameters include the absolute neutrophil count and ratio of immature to total cells within the neutrophil series (I:T ratio) (67). Evaluation of biochemical markers associated with the host inflammatory response, such as C-reactive protein (CRP) $(67,68)$, may also used. CRP requires 8 to 10 hours for synthesis making it much more sensitive in the later phase of infection. Serial CRPs (two levels obtained 24 hours apart, 8-48 hours after presentation) have a reported sensitivity of $80 \%$ to $90 \%$ and negative predictive value of $99 \%$ (69). The low sensitivity of CRP early in sepsis progression makes withholding initiation of antibiotics based on a low, early CRP value inadvisable, but serial CRPs may be useful in determining the duration of antibiotic course.

Approximately one-fourth to one-third of infants with sepsis also has meningitis (70). Among symptomatic infants, consideration of performance of lumbar puncture for examination and culture of cerebrospinal fluid is important as meningitis (pleocytosis, increased protein, hypoglycorrhachia, and positive culture) will determine duration and type of antibiotic treatment. Because viral and bacterial infections may present similarly, testing for viruses, particularly herpes simplex virus, in blood and spinal fluid should also be considered (see Chapter 74). Beyond the first few days of life, evaluation and culture of urine by catheterization or suprapubic bladder aspiration are also indicated to identify potential urinary tract foci of infection. Additional testing should be based on clinical findings and may include radiologic evaluation of the chest and abdomen.

Rapidity of progression of sepsis in the newborn infant requires prompt initiation of antibiotics once cultures have been obtained. The choice of empiric antibiotic therapy should be based on the timing and setting of infection (EOS vs. LOS, community vs. NICU) as well as the profile of microorganisms and their susceptibility patterns among specific populations. For EOS, a combination of ampicillin and gentamicin is frequently used. If meningitis is suspected, consideration should be given to addition of cefotaxime for its improved cerebrospinal fluid penetration. For LOS, therapy should be tailored to the individual patient, her/his risk factors, and past microbial flora. The frequencies of CONS, MRSA, and gramnegative organisms have resulted in the common use of vancomycin and an aminoglycoside. A worsening clinical course should result in consideration of broadening of coverage to include Pseudomonas species, drug-resistant gram negatives, and common fungi (e.g., Candida). Isolated bacteremia without meningitis or other focus is treated with 7 to 10 days of antibiotics. Treatment is otherwise largely supportive, with close monitoring and intervention for respiratory failure, hypotension, and central nervous system disturbances. Given the compromised immune response of the newborn infant, several immunologic therapies have also been investigated (71-73) of which only intravenous immune globulin has demonstrated a statistically significant reduction in mortality in cases of subsequently proven infection (71).

\section{NEWBORN SCREENING FOR METABOLIC DISORDERS}

Newborn screening for metabolic disorders is the most widely performed genetic testing in the United States. Nearly all of the more than 4 million infants born each year undergo newborn metabolic screening. The specific battery of screening tests is determined by individual state statute. As of 2005, the number of different screening tests performed varied from 4 to 46 among the states (74). Funding for the screening programs and follow-up services also varies from state to state. Ninety percent of the state screening programs have a fee paid by the family or third party payer, $61 \%$ receive funds from the Maternal and Child Health Services Title V block grant, 33\% rely on at least partial funding from state general revenues, and 24\% receive direct Medicaid reimbursement (75). In addition to the screening programs in the United States, most developed and many developing countries have newborn screening programs (76-79).

Newborn metabolic screening was introduced in the 1960s with the development by Robert Guthrie of a bacterial assay for phenylalanine used for the diagnosis of phenylketonuria. 
Table 2 ACMG Recommendations for Newborn Screening

Core panel

Organic acid metabolic defects

Isovaleric acidemia

Glutaric acidemia type I

3-Hydroxy-3-methylglutaric aciduria

Multiple carboxylase deficiency

Methylmalonic academia (mutase)

3-Methylcrotonyl-CoA-carboxylase deficiency

Methylmalonic acidemia (Cbl A, B)

Propionic acidemia

$\beta$-Ketothiolase deficiency

Fatty acid oxidation disorders

Medium-chain acyl-CoA dehydrogenase deficiency

Very long-chain acyl-CoA dehydrogenase deficiency

Long chain L-3-hydroxyacyl-CoA dehydrogenase deficiency

Trifunctional protein deficiency

Carnitine uptake deficiency

Amino acid metabolism disorders

Phenylketonuria

Maple syrup disease

Homocystinuria

Citrullinemia

Argininosuccinic academia

Tyrosinemia type I

\section{Hemoglobinopathies}

Sickle cell anemia (Hb SS)

Hemoglobin $S / \beta$-thalassemia

Hemoglobin S/C disease

Other

Congenital hypothyroidism

Biotinidase deficiency

Congenital adrenal hyperplasia (21-hydroxylase deficiency)

Classic galactosemia

Hearing loss

Cystic fibrosis

Guthrie's other major contribution to newborn screening was a method for using a dried infant blood spot on filter paper (the eponymous "Guthrie card") that allows for easy collection and processing of a large number of samples (80). As additional assays were developed that could be performed on blood spots, the scope of newborn metabolic screening was expanded. Criteria for inclusion of a test in the screening panel include benefit of early detection due to availability of an effective treatment, availability of a test with appropriate sensitivity and specificity, and opportunity for early detection of a potentially treatable condition during the neonatal period when it might otherwise not be clinically apparent (81). Screening programs should also provide mechanisms for appropriate confirmatory testing as well as referral for counseling and management.

With the recent development of tandem mass spectroscopic (MS/MS) methods to detect metabolites on Guthrie cards, there has been a major expansion in the metabolic diseases for which screening is now available. In 2005, the American College of Medical Genetics recommended that all states begin
Secondary targets

Methylmalonic acidemia (Cbl C,D)

Malonic acidemia

Isobutyryl-CoA dehydrogenase deficiency

2-Methylbutyrl-CoA dehydrogenase deficiency

2-Methyl-3-hydroxybutyric aciduria

3-Methylglutaconic aciduria

Short-chain acyl-CoA dehydrogenase deficiency

Glutaric acidemia type II

Medium/short-chain L-3-hydroxyacyl-CoA dehydrogenase deficiency

Medium-chain ketoacyl-CoA thiolase deficiency

Carnitine palmitoyltransferase II deficiency

Carnitine/acylcarnitine translocase deficiency

Carnitine palmitoyltransferase I deficiency

Dienoyl-CoA reductase deficiency

Benign hyperphenylalaninemia

Tyrosinemia type II

Biopterin cofactor metabolism defects

Argininemia

Tyrosinemia type III

Biopterin cofactor regeneration defects

Hypermethioninemia

Citrullinemia type II

Variant hemoglobinopathies

Galactokinase deficiency

Galactose epimerase deficiency screening for 29 core conditions plus an additional 25 conditions (secondary targets) that can be detected by the screening methods but may not have an effective therapy or their natural history may not be well understood (82). Table 2 lists the recommended screening tests. This list includes some assays that utilize methods other than MS/MS. Although this recommendation has been controversial, it has been endorsed by the American Academy of Pediatrics $(81,83,84)$. The American College of Obstetrics and Gynecology has also issued a supportive opinion (85). This building consensus has resulted in an increase in the number of tests included on the screening panels in most states (74). In the future, as DNA microarray technology advances and becomes less costly, newborn metabolic screening may also incorporate this technology (86).

\section{REFERENCES}

1. Rubaltelli FF, Dani C, Reali MF, et al. Acute neonatal respiratory distress in Italy: a one-year prospective study. Italian Group of Neonatal Pneumology. Acta Paediatr 1998; 87: 1261-8. 
2. Gouyon JB, Ribakovsky C, Ferdynus C, et al. Severe respiratory disorders in term neonates. Paediatr Perinat Epidemiol 2008; 22: 22-30.

3. Cayabyab RG, Kwong K, Jones C, Minoo P, Durand M. Lung inflammation and pulmonary function in infants with meconium aspiration syndrome. Pediatr Pulmonol 2007; 42: 898-905.

4. Thureen PJ, Hall DM, Hoffenberg A, Tyson RW. Fatal meconium aspiration in spite of appropriate perinatal airway management: pulmonary and placental evidence of prenatal disease. Am J Obstet Gynecol 1997; 176: 967-75.

5. Wiswell TE, Tuggle JM, Turner BS. Meconium aspiration syndrome: have we made a difference? Pediatrics 1990; 85: 715-21.

6. Dargaville PA, Copnell B. The epidemiology of meconium aspiration syndrome: incidence, risk factors, therapies, and outcome. Pediatrics 2006; 117: 1712-21.

7. International Consensus on Cardiopulmonary Resuscitation and Emergency Cardiovascular Care Science with Treatment Recommendations. Part 7: neonatal resuscitation. Resuscitation 2005; 67: 293-303.

8. Vain NE, Szyld EG, Prudent LM, et al. Oropharyngeal and nasopharyngeal suctioning of meconium-stained neonates before delivery of their shoulders: multicentre, randomised controlled trial. Lancet 2004; 364: 597-602.

9. ACOG Committee Opinion Number 346. Amnioninfusion does not prevent meconium aspiration syndrome. Obstet Gynecol 2006; 108: 1053

10. ACOG Committee Opinion No. 379. Management of delivery of a newborn with meconium-stained amniotic fluid. Obstet Gynecol 2007; 110: 739 .

11. Avery ME, Gatewood OB, Brumley G. Transient tachypnea of newborn. Possible delayed resorption of fluid at birth. Am J Dis Child 1966; 111: 380-5.

12. Barker PM, Olver RE. Invited review: clearance of lung liquid during the perinatal period. J Appl Physiol 2002; 93: 1542-8.

13. Aslan E, Tutdibi E, Martens S, et al. Transient tachypnea of the newborn (TTN): a role for polymorphisms in the beta-adrenergic receptor (ADRB) encoding genes? Acta Paediatr 2008; 97: 1346-50.

14. Villar J, Carroli G, Zavaleta N, et al. Maternal and neonatal individual risks and benefits associated with caesarean delivery: multicentre prospective study. BMJ 2007; 335: 1025.

15. Balchin I, Whittaker JC, Lamont RF, Steer PJ. Timing of planned cesarean delivery by racial group. Obstet Gynecol 2008; 111: 659-66.

16. Hansen AK, Wisborg K, Uldbjerg N, Henriksen TB. Risk of respiratory morbidity in term infants delivered by elective caesarean section: cohort study. BMJ 2008; 336: 85-7.

17. Martin JA, Kung HC, Mathews TJ, et al. Annual summary of vital statistics: 2006. Pediatrics 2008; 121: 788-801.

18. Stevens TP, Sinkin RA. Surfactant replacement therapy. Chest 2007; 131: 1577-82.

19. Fraser J, Walls M, McGuire W. Respiratory complications of preterm birth. BMJ 2004; 329: 962-5.

20. Clark RH. The epidemiology of respiratory failure in neonates born at an estimated gestational age of 34 weeks or more. J Perinatol 2005; 25: 251-7.

21. Avery ME, Mead J. Surface properties in relation to atelectasis and hyaline membrane disease. AMA J Dis Child 1959; 97(5 Pt 1): 517-23.

22. Soll RF, Morley CJ. Prophylactic versus selective use of surfactant in preventing morbidity and mortality in preterm infants. Cochrane Database Syst Rev 2001: CD000510.

23. Yost CC, Soll RF. Early versus delayed selective surfactant treatment for neonatal respiratory distress syndrome. Cochrane Database Syst Rev 2000: CD001456.

24. Cerny L, Torday JS, Rehan VK. Prevention and treatment of bronchopulmonary dysplasia: contemporary status and future outlook. Lung 2008; 186: 75-89.

25. Geary C, Caskey M, Fonseca R, Malloy M. Decreased incidence of bronchopulmonary dysplasia after early management changes, including surfactant and nasal continuous positive airway pressure treatment at delivery, lowered oxygen saturation goals, and early amino acid administration: a historical cohort study. Pediatrics 2008; 121: 89-96.

26. Stevens TP, Harrington EW, Blennow M, Soll RF. Early surfactant administration with brief ventilation vs. selective surfactant and continued mechanical ventilation for preterm infants with or at risk for respiratory distress syndrome. Cochrane Database Syst Rev 2007: CD003063.

27. Liggins GC. Premature delivery of foetal lambs infused with glucocorticoids. J Endocrinol 1969; 45: 515-23.

28. Liggins GC, Howie RN. A controlled trial of antepartum glucocorticoid treatment for prevention of the respiratory distress syndrome in premature infants. Pediatrics 1972; 50: 515-25.

29. Roberts D, Dalziel S. Antenatal corticosteroids for accelerating fetal lung maturation for women at risk of preterm birth. Cochrane Database Syst Rev 2006; 3: CD004454.

30. O'Shea TM, Washburn LK, Nixon PA, Goldstein DJ. Follow-up of a randomized, placebo-controlled trial of dexamethasone to decrease the duration of ventilator dependency in very low birth weight infants: neurodevelopmental outcomes at 4 to 11 years of age. Pediatrics 2007; 120: 594-602.

31. Wilson-Costello D, Friedman H, Minich N, et al. Improved neurodevelopmental outcomes for extremely low birth weight infants in 2000-2002. Pediatrics 2007; 119: 37-45.

32. Hamvas A, Cole FS, Nogee LM. Genetic disorders of surfactant proteins. Neonatology 2007; 91: 311-17.

33. Karjalainen MK, Haataja R, Hallman M. Haplotype analysis of ABCA3: association with respiratory distress in very premature infants. Ann Med 2008; 40: 56-65.

34. Lahti M, Marttila R, Hallman M. Surfactant protein C gene variation in the Finnish population - association with perinatal respiratory disease. Eur J Hum Genet 2004; 12: 312-20.

35. Marttila R, Haataja R, Guttentag S, Hallman M. Surfactant protein A and $\mathrm{B}$ genetic variants in respiratory distress syndrome in singletons and twins. Am J Respir Crit Care Med 2003; 168: 1216-22.

36. Capasso M, Avvisati RA, Piscopo C, et al. Cytokine gene polymorphisms in Italian preterm infants: association between interleukin-10 -1082 G/A polymorphism and respiratory distress syndrome. Pediatr Res 2007; 61: 313-17.

37. Hilgendorff A, Heidinger K, Pfeiffer A, et al. Association of polymorphisms in the mannose-binding lectin gene and pulmonary morbidity in preterm infants. Genes Immun 2007; 8: 671-7.

38. Pulkkinen V, Haataja R, Hannelius U, et al. G protein-coupled receptor for asthma susceptibility associates with respiratory distress syndrome. Ann Med 2006; 38: 357-66.

39. Raju TN, Higgins RD, Stark AR, Leveno KJ. Optimizing care and outcome for late-preterm (near-term) infants: a summary of the workshop sponsored by the National Institute of Child Health and Human Development. Pediatrics 2006; 118: 1207-14.

40. Raju TN. Epidemiology of late preterm (near-term) births. Clin Perinatol 2006; 33: 751-63; abstract vii.

41. Davidoff MJ, Dias T, Damus K, et al. Changes in the gestational age distribution among U.S. singleton births: impact on rates of late preterm birth, 1992 to 2002. Semin Perinatol 2006; 30: 8-15.

42. Sibai BM. Preeclampsia as a cause of preterm and late preterm (nearterm) births. Semin Perinatol 2006; 30: 16-19.

43. Florica M, Stephansson O, Nordstrom L. Indications associated with increased cesarean section rates in a Swedish hospital. Int J Gynaecol Obstet 2006; 92: 181-5.

44. Quinlivan JA, Petersen RW, Nichols CN. Patient preference the leading indication for elective Caesarean section in public patients-results of a 2-year prospective audit in a teaching hospital. Aust NZ J Obstet Gynaecol 1999; 39: 207-14.

45. Wang ML, Dorer DJ, Fleming MP, Catlin EA. Clinical outcomes of nearterm infants. Pediatrics 2004; 114: 372-6.

46. Hunt CE. Ontogeny of autonomic regulation in late preterm infants born at 34-37 weeks postmenstrual age. Semin Perinatol 2006; 30: 73-6.

47. Dudell GG, Jain L. Hypoxic respiratory failure in the late preterm infant. Clin Perinatol 2006; 33: 803-30; abstract viii-ix.

48. Kramer MS, Demissie K, Yang H, et al. The contribution of mild and moderate preterm birth to infant mortality. Fetal and Infant Health Study Group of the Canadian Perinatal Surveillance System. JAMA 2000; 284: 843-9.

49. Jain S, Cheng J. Emergency department visits and rehospitalizations in late preterm infants. Clin Perinatol 2006; 33: 935-45; abstract xi. 
50. Tomashek KM, Shapiro-Mendoza CK, Weiss J, et al. Early discharge among late preterm and term newborns and risk of neonatal morbidity. Semin Perinatol 2006; 30: 61-8.

51. Shapiro-Mendoza CK, Tomashek KM, Kotelchuck M, et al. Risk factors for neonatal morbidity and mortality among "healthy," late preterm newborns. Semin Perinatol 2006; 30: 54-60.

52. Kinney HC. The near-term (late preterm) human brain and risk for periventricular leukomalacia: a review. Semin Perinatol 2006; 30: 81-8.

53. Chyi LJ, Lee HC, Hintz SR, Gould JB, Sutcliffe TL. School outcomes of late preterm infants: special needs and challenges for infants born at 32 to 36 weeks gestation. J Pediatr 2008; 153: 25-31.

54. Heron M. Deaths: leading causes for 2004. Natl Vital Stat Rep 2007; 56: 1-95.

55. Bizzarro MJ, Raskind C, Baltimore RS, Gallagher PG. Seventy-five years of neonatal sepsis at Yale: 1928-2003. Pediatrics 2005; 116: 595-602.

56. Stoll BJ, Holman RC, Schuchat A. Decline in sepsis-associated neonatal and infant deaths in the United States, 1979 through 1994. Pediatrics 1998; 102: e18.

57. Stoll BJ, Hansen N. Infections in VLBW infants: studies from the NICHD Neonatal Research Network. Semin Perinatol 2003; 27: 293-301.

58. Baltimore RS, Huie SM, Meek JI, Schuchat A, O’Brien KL. Early-onset neonatal sepsis in the era of group B streptococcal prevention. Pediatrics 2001; 108: 1094-8.

59. Hyde TB, Hilger TM, Reingold A, et al. Trends in incidence and antimicrobial resistance of early-onset sepsis: population-based surveillance in San Francisco and Atlanta. Pediatrics 2002; 110: 690-5.

60. Stoll BJ, Hansen N, Fanaroff AA, et al. Changes in pathogens causing early-onset sepsis in very-low-birth-weight infants. N Engl J Med 2002; 347: 240-7.

61. Stoll BJ, Hansen NI, Higgins RD, et al. Very low birth weight preterm infants with early onset neonatal sepsis: the predominance of gramnegative infections continues in the National Institute of Child Health and Human Development Neonatal Research Network, 2002-2003. Pediatr Infect Dis J 2005; 24: 635-9.

62. Phares CR, Lynfield R, Farley MM, et al. Epidemiology of invasive group B streptococcal disease in the United States, 1999-2005. JAMA 2008; 299: 2056-65.

63. Voora S, Srinivasan G, Lilien LD, Yeh TF, Pildes RS. Fever in full-term newborns in the first four days of life. Pediatrics 1982; 69: 40-4.

64. Fanaroff AA, Korones SB, Wright LL, et al. Incidence, presenting features, risk factors and significance of late onset septicemia in very low birth weight infants. The National Institute of Child Health and Human Development Neonatal Research Network. Pediatr Infect Dis J 1998; 17: 593-8.

65. Sarkar S, Bhagat I, DeCristofaro JD, Wiswell TE, Spitzer AR. A study of the role of multiple site blood cultures in the evaluation of neonatal sepsis. J Perinatol 2006; 26: 18-22.

66. Wiswell TE, Hachey WE. Multiple site blood cultures in the initial evaluation for neonatal sepsis during the first week of life. Pediatr Infect Dis J 1991; 10: 365-9.
67. Ng PC. Diagnostic markers of infection in neonates. Arch Dis Child Fetal Neonatal Ed 2004; 89: F229-35.

68. Lam HS, Ng PC. Biochemical markers of neonatal sepsis. Pathology 2008; 40: $141-8$.

69. Benitz WE, Han MY, Madan A, Ramachandra P. Serial serum C-reactive protein levels in the diagnosis of neonatal infection. Pediatrics 1998; 102: E41.

70. Baltimore R. Perinatal bacterial and fungal infections. In: Jenson HB, Baltimore RS, eds. Pediatric Infectious Diseases: Principles and Practice, 2nd edn. Baltimore: W.B. Saunders, 2002.

71. Ohlsson A, Lacy JB. Intravenous immunoglobulin for suspected or subsequently proven infection in neonates. Cochrane Database Syst Rev 2004: CD001239.

72. Mohan P, Brocklehurst P. Granulocyte transfusions for neonates with confirmed or suspected sepsis and neutropaenia. Cochrane Database Syst Rev 2003: CD003956.

73. Carr R, Modi N, Dore C. G-CSF and GM-CSF for treating or preventing neonatal infections. Cochrane Database Syst Rev 2003: CD003066.

74. Tarini BA, Christakis DA, Welch HG. State newborn screening in the tandem mass spectrometry era: more tests, more false-positive results. Pediatrics 2006; 118: 448-56.

75. Therrell BL, Williams D, Johnson K, et al. Financing newborn screening: sources, issues, and future considerations. J Public Health Manag Pract 2007; 13: 207-13.

76. Bodamer OA, Hoffmann GF, Lindner M. Expanded newborn screening in Europe 2007. J Inherit Metab Dis 2007; 30: 439-44.

77. Borrajo GJ. Newborn screening in Latin America at the beginning of the 21st century. J Inherit Metab Dis 2007; 30: 466-81.

78. Padilla CD, Therrell BL. Newborn screening in the Asia Pacific region. J Inherit Metab Dis 2007; 30: 490-506.

79. Saadallah AA, Rashed MS. Newborn screening: experiences in the Middle East and North Africa. J Inherit Metab Dis 2007; 30: 482-9.

80. Guthrie R, Susi A. A simple phenylalanine method for detecting phenylketonuria in large populations of newborn infants. Pediatrics 1963; 32: 338-43.

81. Watson M, Mann MY, Lloyd-Puryear MA, et al. Newborn screening: toward a uniform screening panel and system-executive summary. Pediatrics 2006; 117(5 Pt 2): S296-307.

82. Watson M, Lloyd-Puryear MA, Mann MY, et al. Newborn screening: toward a uniform screening panel and system. Genet Med 2006; 8: 12S-252S

83. Baily MA, Murray TH. Ethics, evidence, and cost in newborn screening. Hastings Cent Rep 2008; 38: 23-31.

84. Moyer VA, Calonge N, Teutsch SM, Botkin JR. Expanding newborn screening: process, policy, and priorities. Hastings Cent Rep 2008; 38: 32-9.

85. ACOG Committee Opinion No. 393. Newborn screening. Obstet Gynecol 2007; 110: 1497-500.

86. Green NS, Pass KA. Neonatal screening by DNA microarray: spots and chips. Nat Rev Genet 2005; 6: 147-51. 